( 2018 , The Authors. Published by FASS Inc. and Elsevier Inc. on behalf of the American Dairy Science Association ${ }^{\circledR}$.

This is an open access article under the CC BY-NC-ND license (http://creativecommons.org/licenses/by-nc-nd/4.0/).

\title{
Additive genetic and heterosis effects for milk fever in a population of Jersey, Holstein $\times$ Jersey, and Holstein cattle under grazing conditions
}

\author{
A. Saborío-Montero, ${ }^{* 1}$ B. Vargas-Leitón, $\dagger$ J. J. Romero-Zúñiga, $†$ and J. Camacho-Sandoval† \\ *Animal Nutrition Research Center and Animal Science Department, University of Costa Rica, San José 11501, Costa Rica \\ †Population Medicine Research Program, Veterinary Medicine School, National University of Costa Rica, Heredia 40104, Costa Rica
}

\begin{abstract}
The aim of this study was to estimate additive genetic and heterosis effects for milk fever (MF) in Costa Rican dairy cattle. A farm-based management information software was used to collect 223,783 parity records between years 1989 and 2016, from 64,008 cows, 2 breeds (Jersey, Holstein $\times$ Jersey crosses, and Holstein), and 134 herds. The pedigree file comprised 73,653 animals distributed across 10 generations. A total of 4,355 $(1.95 \%)$ clinical cases of MF were reported within this population, affecting 3,469 $(5.42 \%)$ cows. Data were analyzed using 2 animal models, both accounting for repeatability and assuming different distributions for MF event: normal (linear model) or binomial (threshold model). The models included parity as fixed effect, breed and heterosis as fixed regressions, and herd-yearseason, additive genetic, and permanent environment as random effects. The models were fit using a generalized linear mixed model approach, as implemented in ASReml 4.0 software. We noted significant regression on the percentage of Holstein breed, depicting a $-0.0086 \%$ [standard error $(\mathrm{SE})=0.0012]$ decrease in MF incidence for each 1-unit increase in percentage of Holstein breed. A favorable heterosis of $5.9 \%$ for MF was found, although this was not statistically significant. Heritability and repeatability were, respectively, $0.03(\mathrm{SE}=$ $0.002)$ and $0.05(\mathrm{SE}=0.002)$ for the linear model, and $0.07(\mathrm{SE}=0.007)$ and $0.07(\mathrm{SE}=0.007)$ for the threshold model. The correlation between BLUP (all animals in pedigree) for linear and threshold models, was 0.89. The average accuracy of the estimated BLUP for all animals were 0.44 (standard deviation $=0.13$ ) for the linear model and 0.29 (standard deviation $=0.14$ ) for the threshold model. Heritability and repeatability for MF within this population was low, though significant.
\end{abstract}

Received December 2, 2017.

Accepted June 8, 2018.

${ }^{1}$ Corresponding author: alejandro.saboriomontero@ucr.ac.cr
Key words: milk fever, heritability, repeatability, heterosis

\section{INTRODUCTION}

Clinical hypocalcemia in dairy cattle, also known as milk fever (MF; Horst et al., 1997), is a metabolic disease characterized by clinical symptoms due to reduction of blood calcium concentration during peripartum, which affects high-yielding multiparous cows (NRC, 2001). A low proportion of females (2-7\%) suffer MF (Roche, 2003; Goff, 2008); however, affected cows reduce productive and reproductive performance, causing economic losses (Guard, 1996; Kossaibati and Esslemont, 1996). Ethical issues regarding MF, from an animal welfare approach, also exist.

Previous studies have shown greater susceptibility to MF in the Jersey breed compared with the Holstein breed, whereas Holstein $\times$ Jersey crossbred cows have shown intermediate risk of suffering the disease. A meta-analysis by Lean et al. (2006) showed that Jersey cows had 2.37 times the risk of having MF compared with the Holstein breed. Likewise, Roche and Berry (2006) found, in grazing systems, that Jersey cows and Holstein $\times$ Jersey crossbred cows had 4.96 and 2.44 times the chance of suffer MF, respectively, compared with Holstein cows. More recently, Saborío-Montero et al. (2017), in a grazing population, reported that Jersey cows, Holstein $\times$ Jersey crossbred cows, and Holstein cows had 3.04, 2.53, and 1.61 times the chance of occurrence of MF compared with Brown Swiss breed cows. Whether these differences are due to genetic factors or differential management between breeds is not clear from previous studies. Potential heterosis effects for MF, on the other hand, have not been reported in the literature.

Estimates of genetic parameters for MF vary depending on the genetic model (animal vs. sire models) and the distribution assumed (linear vs. threshold), the number of traits in the model (univariate vs. multivariate), or parity number (first calving vs. multiparous cows), among others factors. Uribe et al. (1995) esti- 
mated a heritability of 0.09 for MF using a threshold sire model. Heringstad et al. (2005), using a similar model, determined heritabilities of $0.09,0.11$, and 0.13 for first-, second-, and third-calving cows, respectively. Another study by Kadarmideen et al. (2000) obtained heritabilities of 0.012 and 0.065 and repeatabilities of 0.039 and 0.065 from multitrait linear and threshold animal models, respectively. For first-parity cows, Van Dorp et al. (1998) obtained heritability of 0.04 using a univariate linear animal model, whereas Tveit et al. (1991) obtained an estimate of 0.11 from a multitrait linear animal model. For multiparous cows, Koeck et al. (2015) found an estimate of 0.01 using a univariate linear sire model. Larger heritabilities for MF have been reported, in the order of 0.30 (Lin et al., 1989) and 0.40 (Lyons et al., 1991), both using a linear sire model, or 0.35 (Abdel-Azim et al., 2005) from a threshold sire model, the latter with standard error of 0.18. In general, higher estimates of heritability for MF are observed when sire models are used compared with animal models.

To the best of our knowledge, the heterosis effect for MF has not been studied yet. The analysis of the heterosis effect for MF is an innovative contribution that we will address in the current paper. Our study aims to determine the relative contributions of additive genetic and heterosis effects on MF in grazing dairy cattle to explore the genetic background of this imbalance. Genetic selection might be a useful tool contributing to an integral approach focused on reduction of MF.

\section{MATERIALS AND METHODS}

\section{Study Design}

A longitudinal observational study design was used to analyze health data regarding MF from records collected in the Veterinary Automated Management and Production Control Program software (Noordhuizen and Buurman, 1984) between 1989 and 2016. The study population consisted of 64,008 cows, 2 breeds (Holstein, Jersey, and Holstein $\times$ Jersey crosses) from 134 herds, with a total of 223,783 recorded parities along 10 generations of cows in pedigree in Costa Rica.

The follow-up period varied widely between herds, from a minimum of $3 \mathrm{yr}$ to a maximum of $28 \mathrm{yr}$, with an average of $19.4 \mathrm{yr}$. To eliminate herds that did not register MF events on a regular basis, only those herds that reported at least 5 cases of MF were included in the study. A minimum of 5 cows within herd-year-season was also required. Consistency checks were performed on individual animal data regarding the logical sequence of reproductive events and genealogical records.
Cases of MF reported during the first 12 wk after calving were included in the analysis, although $75 \%$ of cases occurred immediately after calving and 90\% within the first $3 \mathrm{wk}$ after calving. For this study, we assumed that a reasonably accurate diagnosis of MF was made by herd managers based on symptomology, such as those mentioned by Horst et al. (1997), as well as the time of development of symptoms relative to calving and response of the cow to treatment with intravenous calcium.

\section{Statistical Analysis}

Several statistical and genetic models have been used in the analysis of categorical events, such as MF (Gianola, 1980, 1982). The use of nonlinear mixed models based on threshold theory has been suggested a more appropriate alternative to linear models (Gianola, 1982; Gianola and Foulley, 1983; Kadarmideen et al., 2000). Threshold model is based in the postulate that the binomial response variable is indeed a subjacent continuous variable that takes a value of 1 if it exceeds a fixed threshold value and a value of 0 if it does not (Heringstad et al., 2005).

Two statistical models were evaluated, defined as linear-animal model (LA) and threshold-animal model (TA). Linear and threshold are referred to the dependent variable (MF). For LA a normal distribution with identity link function was assumed, whereas for TA a binomial distribution with a probit link function was used. Equation 1 describes the effects included in both models:

$$
\begin{aligned}
y=\mu+P+H Y S & +\beta_{1} \times(\% \text { Hol })+\beta_{2} \times(\% \text { het }) \\
& +a+p+\varepsilon,
\end{aligned}
$$

where $y=$ occurrence of milk fever event (recorded as: $0 / 1=$ absent $/$ present $) ; \mu=$ general mean; $P=$ fixed effect of parity ( 6 classes, from 1 to $\geq 6$ ); HYS = random effect of herd-year-season of calving, with season arranged in 3-mo length periods (9,699 classes); $\beta_{1} \times$ $(\% \mathrm{Hol})=$ linear regression on the percentage of Holstein breed, as Holstein $(\mathbf{H})=100 \%$, Jersey $(\mathbf{J})=0 \%$, $3 / 4 \mathrm{H} 1 / 4 \mathrm{~J}=75 \%, 1 / 2 \mathrm{H} 1 / 2 \mathrm{~J}=50 \%$, and $1 / 4 \mathrm{H} 3 / 4 \mathrm{~J}$ $=25 \% ; \beta_{2} \times(\%$ het $)=$ linear regression on the expected percentage of heterosis retained (VanRaden, 1992) according to breed type, as $\mathrm{H}=0 \%, \mathrm{~J}=0 \%$, $3 / 4 \mathrm{H} 1 / 4 \mathrm{~J}=50 \%, 1 / 2 \mathrm{H} 1 / 2 \mathrm{~J}=100 \%, 1 / 4 \mathrm{H} 3 / 4 \mathrm{~J}=$ $50 \% ; a=$ random additive genetic effect linked to pedigree $(\mathrm{n}=73,653) ; p=$ random permanent environment effect $(\mathrm{n}=64,008)$; and $\varepsilon=$ Random residual error, $N\left(0, \sigma_{e}^{2}\right)$, where $\sigma_{e}^{2}$ is the residual variance. Herds 
practicing crossbreeding alternate purebred sires, therefore $1 / 2 \mathrm{H} 1 / 2 \mathrm{~J}$ cows were all $\mathrm{F}_{1}$, and $3 / 4$ to $1 / 4$ cows were the result of backcrossing $\mathrm{F}_{1}$ to Holstein or Jersey. A few cows from further alternate crosses were initially present in the data set, but not used in this analysis. Both models were solved using generalized linear mixed models in ASReml software (Gilmour et al., 2009). This software uses penalized quasi-likelihood, which is based on Taylor's first order proximity series.

The Wald's conditional F test was used to infer about fixed effects, as this test estimates each fixed effect of the linear model maintaining marginality of relationships by the method of Kenward and Roger (1997). In this way, an $\mathrm{F}$ test for the mean was also obtained by ignoring the fixed effect of parity.

Percentage of heterosis (\% het) was calculated as in Equation [2] (Bourdon, 1997), which is self-explanatory:

$$
\% \text { het }=\left[\frac{\left(F_{1} \text { average }- \text { Purebred average }\right)}{\text { Purebred average }}\right] \times 100 .[2]
$$

Predicted incidences of MF by parity and for different combinations of breed and heterosis effects were obtained from the solutions of LA and TA models.

For estimation of heritability and repeatability, additive genetic variance was obtained directly from the animal variance component, whereas phenotypic variance was calculated as the sum of herd-year-season, animal, permanent environment, and residual variance components. For the linear model, residual variance was estimated directly from optimization algorithm, whereas for threshold model with probit link function, residual variance was fixed to a value of 1 (Gilmour et al., 2009).

Best linear unbiased predictors and corresponding standard errors for animals in the population were obtained from ASREML output. From these, accuracy estimates were calculated using Equation 3. To assess degree of agreement between genetic models, a correlation analysis between BLUP of all animals in pedigree for LA versus TA models was also performed:

$$
\operatorname{Rel}_{i}=\sqrt{\left[1-\frac{s_{i}^{2}}{\left(1+F_{i}\right) \sigma_{A}^{2}}\right]},
$$

where $R e l_{i}=$ accuracy value for BLUP of $i$ th animal; $s_{i}$ $=$ standard error reported for BLUP of $i$ th animal; $F_{i}$ $=$ inbreeding coefficient of $i$ th animal (Bourdon, 1997); and $\sigma_{A}^{2}=$ genetic variance.
Table 1. Number of cows and number of cases and mean incidence of milk fever (MF) per breed group, parity, and overall for a cohort of Jersey, Holstein $\times$ Jersey, and Holstein cattle in 134 grazing dairy herds from 1989 to 2016 in Costa Rica

\begin{tabular}{lccc}
\hline Item & $\begin{array}{c}\text { Population } \\
\text { (no.) }\end{array}$ & $\begin{array}{c}\text { MF Cases } \\
(\text { no. })\end{array}$ & $\begin{array}{c}\text { MF incidence } \\
(\%)\end{array}$ \\
\hline Breed & & & \\
Jersey (J) & 27,297 & 1,868 & 6.84 \\
Holstein (H) & 29,549 & 1,282 & 4.34 \\
1/4H 3/4J & 2,363 & 101 & 4.27 \\
1/2H 1/2J & 3,701 & 194 & 5.24 \\
$3 / 4 \mathrm{H} \mathrm{1/4J}$ & 1,098 & 24 & 2.19 \\
Parity & & & 0.12 \\
1 & 56,965 & 67 & 0.39 \\
2 & 46,421 & 180 & 1.35 \\
3 & 37,496 & 505 & 2.79 \\
4 & 29,305 & 819 & 4.41 \\
5 & 21,495 & 949 & 5.72 \\
6 or more & 32,101 & 1,835 & 5.42 \\
Overall & & & 1.95 \\
By cow & 64,008 & 3,469 & \\
By lactation & 223,783 & 4,355 & \\
\hline
\end{tabular}

\section{RESULTS AND DISCUSSION}

A description of the population, number of cases, and incidence of MF according to breed, parity, and overall is shown in Table 1. Number of records per breed type was very unequal, with purebred Holstein and Jersey providing the vast majority of the data, followed by $\mathrm{F}_{1}$ and backcrosses. Despite this, crossbred cows were present in 118 (88\%) of the herds. Observed incidence of MF was higher in Jersey than in Holstein, intermediate for $\mathrm{F}_{1}$, and lowest for $3 / 4 \mathrm{H} 1 / 4 \mathrm{~J}$ cows. Previous studies have shown greater susceptibility to MF in the Jersey breed compared with the Holstein breed, whereas Holstein $\times$ Jersey crossbred cows have shown intermediate risk to suffering the disease (Lean et al., 2006; Roche and Berry, 2006; Saborío-Montero et al., 2017).

Observed incidence of MF was lower in primiparous cows and increased with parity (Table 1). This effect was determined to be highly significant according to LA and TA models (Table 2). Predicted incidences for MF according to parity, obtained from LA and TA model showed a clear increasing pattern from parity 1 to 6 (Figure 1); these results are also consistent with previous studies (Horst et al., 1997; Lean et al., 2006; Roche and Berry 2006; Reinhardt et al., 2011; SaboríoMontero et al., 2017). Several reasons have been suggested for this effect, such as lower capacity to move calcium from bone in older cows, along with the reduction in transport of intestinal calcium and decrease in production of $1,25-(\mathrm{OH})_{2} \mathrm{D}_{3}$, or the increased colostrum yield in these animals. 
Table 2. Wald's conditional $F$ and $P$-values (in parentheses) in the estimation of heritability and repeatability for milk fever in grazing dairy cattle according to genetic model

\begin{tabular}{lcc}
\hline Parameter & Linear animal & Threshold animal \\
\hline Intercept & $722.4(<0.001)$ & $10,686.6(<0.001)$ \\
Parity & $914.9(<0.001)$ & $509.4(<0.001)$ \\
Linear regression \% Holstein & $48.0(<0.001)$ & $41.2(<0.001)$ \\
Linear regression \% heterosis & $1.1(0.296)$ & $1.77(0.186)$ \\
\hline
\end{tabular}

\section{Breed Differences and Heterosis Effects}

The linear regression on percentage of Holstein was highly significant $(P<0.001)$, whereas the linear regression on percentage of heterosis was not (Table 2). This provides support for the hypothesis of a breed effect partially controlling phenotype for MF occurrence. The predicted incidence of MF according to percentage of Holstein breed showed a well-defined trend of the additive genetic effect affecting risk of suffering MF (Figure 2 ). The linear model predicted a regression coefficient which indicates a $-0.0086 \%(\mathrm{SE}=0.0016)$ decrease in MF incidence for each 1-unit increase in percentage of Holstein breed. Additive differences among breed categories were all significant $(P<0.05)$. Similar trends were obtained from the threshold model.

Previous studies suggested important differences for MF susceptibility between Holstein and Jersey (Lean et al., 2006; Roche and Berry, 2006; Saborío-Montero et al., 2017). The present study suggests that these differences are partially caused by additive genetic effects.

For heterosis, a negative (favorable) regression coefficient of magnitude -0.0014 ( $\mathrm{SE}=0.0013$ ) was found for the linear model, which causes a deviation from breed effects equivalent to a $5.9 \%$ heterosis (Figure 2).

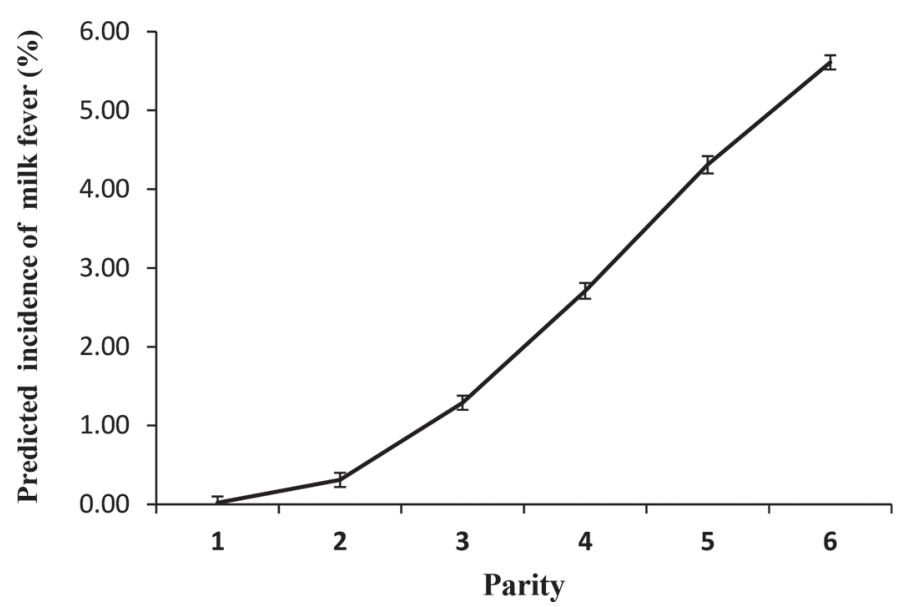

Figure 1. Predicted incidence (estimate \pm SE) of milk fever by parity obtained from linear animal model for a cow with average additive and heterosis covariates.
Estimates from the threshold model also followed the same trend. This deviation, however, was not statistically significant. Suboptimal structure of the data set available may have contributed, to some extent, to the lack of significance for the heterosis effect, given the lower sample size available for crossbred categories and their highly unequal distribution among herds. This is considered relevant because, as far as we know, no other heterosis estimates for MF has been published before.

\section{Heritability and Repeatability for Milk Fever}

Heritability and repeatability for MF from linear and threshold models were both low, though significantly different from zero (Table 3). Estimates were very close to those reported by Kadarmideen et al. (2000), who obtained heritabilities of 0.012 and 0.065 and repeatabilities of 0.039 and 0.065 for MF with LA and TA models, respectively.

Other studies reported similar or slightly higher values for heritability of MF. For first-parity cows, Van Dorp et al. (1998) reported an estimate of 0.04 using a univariate linear animal model, whereas Tveit et al. (1991) obtained an estimate of 0.11 from a multitrait linear animal model. For multiparous cows, Koeck et al. (2015) found an estimate of 0.01 using a univariate linear sire model. Uribe et al. (1995) estimated a heritability of 0.09 for MF using a threshold sire model, whereas Heringstad et al. (2005), using a similar model, determined heritabilities of $0.09,0.11$ and 0.13 for first-, second-, and third-calving cows, respectively. A few studies reported even larger heritabilities, in the order of 0.30 (Lin et al., 1989), 0.35 (Abdel-Azim et al., 2005) and 0.40 (Lyons et al., 1991), all of them using linear or threshold sire models.

Heritabilities found in the present study confirm the existence of substantial within-breed genetic variance for MF propensity in the population under analysis, apart from the aforementioned between-breed additive genetic variance. Milk fever has been related to other peripartum diseases in dairy cattle (Goff, 2008); this does not necessarily indicate a causal relationship, but genetic correlations between metabolic disease traits are mainly positive (Pryce et al., 2016), and therefore 
Table 3. Variance components and the corresponding heritability $\left(h^{2}\right)$ and repeatability $\left(r^{2}\right)$ for milk fever in Costa Rican dairy cattle obtained from linear and threshold animal models

\begin{tabular}{lccccc}
\hline & \multicolumn{2}{c}{ Linear animal model } & & \multicolumn{2}{c}{ Threshold animal model } \\
\cline { 2 - 3 } \cline { 5 - 6 } Variance component & Estimate & SE & & Estimate & SE \\
\hline Residual & 0.0169 & $5.69 \times 10^{-5}$ & & $1.0^{1}$ & \\
Animal & 0.0005 & $3.81 \times 10^{-5}$ & & 0.0967 & 0.0097 \\
Permanent environment & 0.0003 & $4.01 \times 10^{-5}$ & & $0.0^{2}$ & \\
Herd-year-season & 0.0008 & $2.48 \times 10^{-5}$ & & 0.2169 & 0.0103 \\
Phenotypic & 0.0185 & & & & \\
Genetic parameters & & & & 0.07 & 0.007 \\
$\mathrm{~h}^{2}$ & 0.03 & 0.002 & & 0.07 & 0.007 \\
$\mathrm{r}^{2}$ & 0.05 & 0.002 & & & \\
\hline
\end{tabular}

${ }^{1}$ Fixed to 1.0 by ASReml algorithm.

${ }^{2}$ Fixed to a boundary by ASReml algorithm.

selection indexes including MF might have positive effects on improving health related to peripartum disease phenotypes through breeding programs.

All variance components for random effects included in the models satisfactorily converged to unbound solutions, with the exception of variance component for permanent environment in TA model, which was forced to a value of zero in the process of optimization (Table 3). Changes to the TA model did not produce significant differences at this respect, with the estimate of permanent environment always equal or close to zero. This case has also been reported previously when fitting similar TA models (Kadarmideen et al., 2000).
Previously, the penalized quasi-likelihood technic generated estimation biases for some types of generalized linear mixed models (Gilmour et al., 2009, Jang and Lim, 2009). In binary data with small groups, estimation biases can go above 50\% (Breslow and Lin 1995; Goldstein and Rasbash, 1996; Rodriguez and Goldman, 2001; Waddington et al., 1994). Some studies using simulation observed that estimation biases for variance components using penalized quasi-likelihood for threshold models increased with heterogeneity of the random effects (Jang and Lim 2006, 2009), which was the case in our study, given that MF is a low-frequency disease and events do not occur within every herd-year-season.

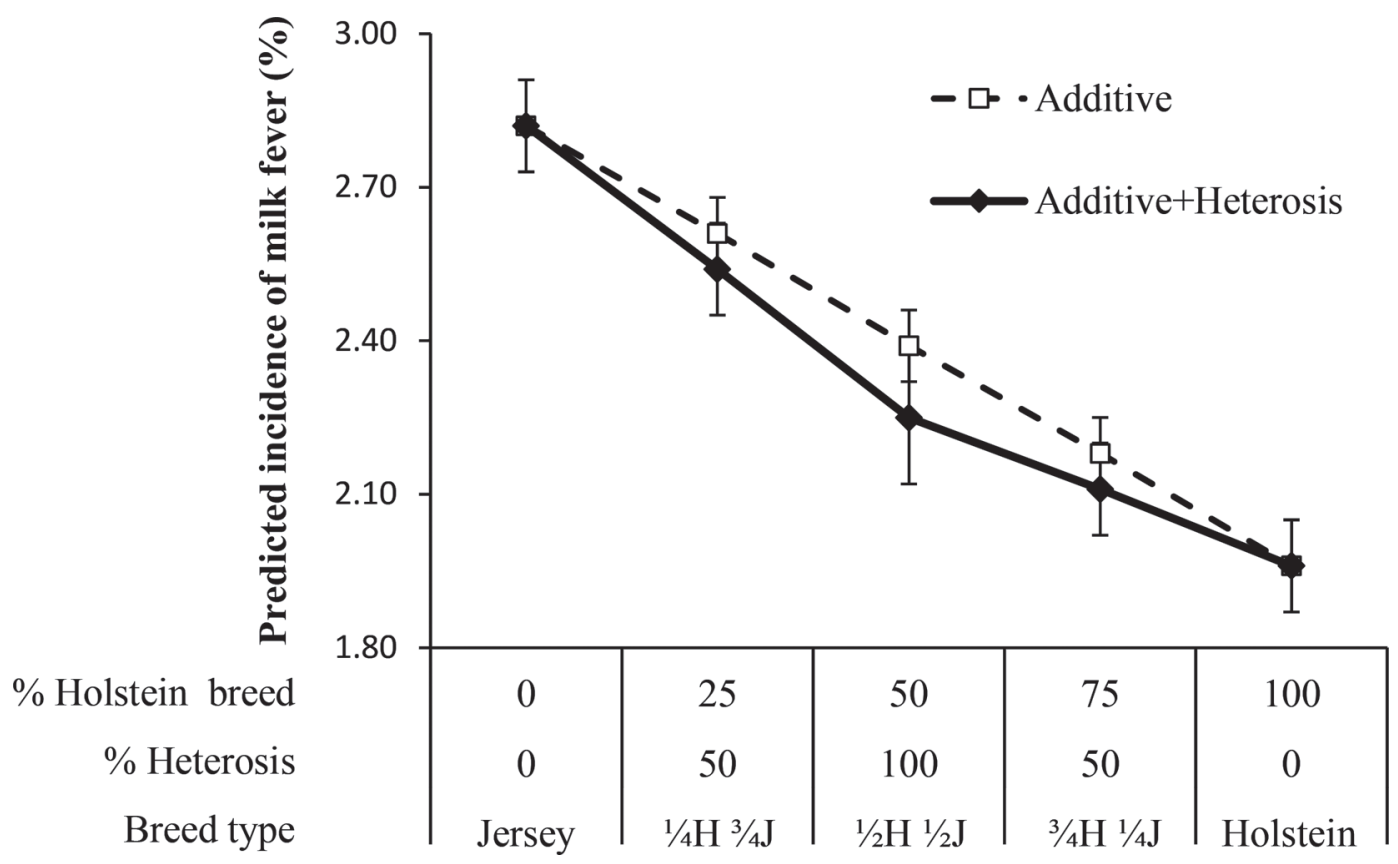

Figure 2. Effect of breed [Holstein $(\mathrm{H})$ or Jersey $(\mathrm{J})]$ and heterosis (estimate \pm SE) on prediction of milk fever for a cow with an average parity obtained from linear animal model. 


\section{BLUP and Accuracy of EBV}

The observed distribution of BLUP indicated that, indistinct from the genetic model, in this population considerably genetic variability for predisposition to MF exists; for instance, BLUP ranged from -0.06 to 0.14 (LA) and from -0.40 to 0.80 (TA, probit scale) for less- to more-susceptible animals for MF. The correlation between BLUP for all animals in the pedigree for TA and LA models was 0.89. These results suggest a strong association between BLUP, assuming different distributions within animal genetic models. The average accuracy of the estimated BLUP were $0.44(\mathrm{SD}=$ $0.13)$ for the linear animal model and $0.29(\mathrm{SD}=0.14)$ for the animal threshold model.

\section{CONCLUSIONS}

Heritability and repeatability for MF were low though significant. We found breed differences partially controlling phenotype for MF occurrence. For heterosis, a favorable (not significant) effect was obtained. Genetic variation for predisposition to MF estimated in this study suggested that inclusion of MF in selection indexes might have positive effects on phenotypes of health related to peripartum diseases through genetic breeding programs. The use of LA or TA leads to a similar ranking of breeding values, which suggests that both models can be used for genetic evaluation of MF.

\section{ACKNOWLEDGMENTS}

The authors acknowledge the Regional Informatics Center for Sustainable Animal Production (CRIPAS) of the Veterinary Medicine School, National University of Costa Rica for allowing us to use the data for this study.

\section{REFERENCES}

Abdel-Azim, G. A., A. E. Freeman, M. E. Kehrli, S. C. Kelm, J. L. Burton, A. L. Kuck, and S. Schnell. 2005. Genetic basis and risk factors for infectious and noninfectious diseases in US Holsteins. I. Estimation of genetic parameters for single diseases and general health. J. Dairy Sci. 88:1199-1207. https://doi.org/10.3168/jds .S0022-0302(05)72786-7.

Bourdon, R. M. 1997. Understanding Animal Breeding. Prentice Hall, Upper Saddle River, NJ.

Breslow, N. E., and X. Lin. 1995. Bias correction in generalised linear mixed models with a single component of dispersion. Biometrika 82:81-91. https://doi.org/10.1093/biomet/82.1.81.

Gianola, D. 1980. Genetic evaluation of animals for traits with categorical responses. J. Anim. Sci. 51:1272. https://doi.org/10.2527/ jas1981.5161272x.

Gianola, D. 1982. Theory and analysis of threshold characters. J. Anim. Sci. 54:1079. https://doi.org/10.2527/jas1982.5451079x.
Gianola, D., and J. L. Foulley. 1983. Sire evaluation for ordered categorical data with a threshold model. Genet. Sel. Evol. 15:201-224.

Gilmour, A. R., B. J. Gogel, B. R. Cullis, and R. Thompson. 2009. ASReml user guide. Release 3.0 VSN International Ltd., Hemel Hempstead, UK.

Goff, J. P. 2008. The monitoring, prevention, and treatment of milk fever and subclinical hypocalcemia in dairy cows. Vet. J. 176:50-57. https://doi.org/10.1016/J.TVJL.2007.12.020.

Goldstein, H., and J. Rasbash. 1996. Improved approximations for multilevel models with Binary Responses. J. R. Stat. Soc. Ser. A Stat. Soc. 159:505. https://doi.org/10.2307/2983328.

Guard, C. 1996. Fresh cow problems are costly: Culling hurts the most. Hoards Dairyman 141:8.

Heringstad, B., Y. M. Chang, D. Gianola, and G. Klemetsdal. 2005. Genetic analysis of clinical mastitis, milk fever, ketosis, and retained placenta in three lactations of Norwegian Red Cows. J. Dairy Sci. 88:3273-3281. https://doi.org/10.3168/jds.S0022 -0302(05)73010-1.

Horst, R. L., J. P. Goff, T. A. Reinhardt, and D. R. Buxton. 1997. Strategies for preventing milk fever in dairy cattle. J. Dairy Sci. 80:1269-1280. https://doi.org/10.3168/JDS.S0022-0302(97)76056 -9 .

Jang, W., and J. Lim. 2006. PQL estimation biases in generalized linear mixed models. Institute of Statistics \& Decision Sciences, Duke University, Durham, NC. Accessed Jul. 25, 2018. ftp://webster .stat.duke.edu/pub/WorkingPapers/05-21.pdf.

Jang, W., and J. Lim. 2009. A numerical study of PQL estimation biases in generalized linear mixed models under heterogeneity of random effects. Commun. Stat. Simul. Comput. 38:692-702.

Kadarmideen, H. N., R. Thompson, and G. Simm. 2000. Linear and threshold model genetic parameters for disease, fertility and milk production in dairy cattle. Anim. Sci. 71:411-419. https://doi.org/ 10.1017/S1357729800055338.

Kenward, M. G., and J. H. Roger. 1997. The precision of fixed effects estimates from restricted maximum likelihood. Biometrics 53:983-997.

Koeck, A., J. Jamrozik, G. J. Kistemaker, F. S. Schenkel, R. K. Moore, D. M. Lefebvre, D. F. Kelton, and F. Miglior. 2015. Development of genetic evaluations for metabolic disease traits for Canadian dairy cattle. Interbull Bull. 49:76-79.

Kossaibati, M. A., and R. J. Esslemont. 1996. DAISY-The Dairy Information System Report $\mathrm{N}^{\circ} 4$. In Wastage in Dairy Herds. Department of Agriculture, Earley Gate. The University of Reading, Reading, UK

Lean, I. J., P. J. DeGaris, D. M. McNeil, and E. Block. 2006. Hypocalcemia in dairy cows: Meta-analysis and dietary cation anion difference theory revisited. J. Dairy Sci. 89:669-684. https://doi .org/10.3168/JDS.S0022-0302(06)72130-0.

Lin, H. K., P. A. Oltenacu, L. D. VanVleck, H. N. Erb, and R. D. Smith. 1989. Heritabilities of and genetic correlations among six health problems in Holstein cows. J. Dairy Sci. 72:180-186. https: //doi.org/10.3168/JDS.S0022-0302(89)79095-0.

Lyons, D. T., A. E. Freeman, and A. L. Kuck. 1991. Genetics of health traits in Holstein cattle. J. Dairy Sci. 74:1092-1100. https://doi .org/10.3168/JDS.S0022-0302(91)78260-X.

National Research Council. 2001. Nutrient Requirements of Dairy Cattle. 7th rev. ed. Natl. Acad. Press, Washington, DC

Noordhuizen, J. P. T. M., and J. Buurman. 1984. VAMPP: A veterinary automated management and production control programme for dairy farms (The application of MUMPS for data processing). Vet. Q. 6:66-72. https://doi.org/10.1080/01652176.1984.9693914.

Pryce, J. E., K. L. Parker Gaddis, A. Koeck, C. Bastin, M. Abdelsayed, N. Gengler, F. Miglior, B. Heringstad, C. Egger-Danner, K. F. Stock, A. J. Bradley, and J. B. Cole. 2016. Invited review: Opportunities for genetic improvement of metabolic diseases. J. Dairy Sci. 99:6855-6873. https://doi.org/10.3168/jds.2016-10854.

Reinhardt, T. A., J. D. Lippolis, B. J. McCluskey, J. P. Goff, and R. L. Horst. 2011. Prevalence of subclinical hypocalcemia in dairy herds. Short communication. Vet. J. 188:122-124.

Roche, J. R. 2003. The incidence and control of hypocalcaemia in pasture-based systems. Acta Vet. Scand. Suppl. 97:141-144. 
Roche, J. R., and D. P. Berry. 2006. Periparturient climatic, animal and management factors influencing the incidence of milk fever in grazing systems. J. Dairy Sci. 89:2775-2783. https://doi.org/10 .3168/JDS.S0022-0302(06)72354-2.

Rodriguez, G., and N. Goldman. 2001. Improved estimation procedures for multilevel models with binary response: A case-study. J. R. Stat. Soc. A Stat. Soc. 164:339-355. https://doi.org/10.1111/ 1467-985X.00206.

Saborío-Montero, A., B. Vargas-Leitón, J. J. Romero-Zúñiga, and J. M. Sánchez. 2017. Risk factors associated with milk fever occurrence in grazing dairy cattle. J. Dairy Sci. 100:9715-9722. https:/ /doi.org/10.3168/jds.2017-13065.

Tveit, B., M. Svendsen, and K. Hove. 1991. Heritability of hypocalcemia at first parturition in Norwegian cattle: genetic correlations with yield and weight. J. Dairy Sci. 74:3561-3567. https://doi.org/ 10.3168/JDS.S0022-0302(91)78548-2.
Uribe, H. A., B. W. Kennedy, S. W. Martin, and D. F. Kelton. 1995 Genetic parameters for common health disorders of Holstein cows. J. Dairy Sci. 78:421-430. https://doi.org/10.3168/JDS.S0022 -0302(95)76651-6.

Van Dorp, T. E., J. C. M. Dekkers, S. W. Martin, and J. P. T. M. Noordhuizen. 1998. Genetic parameters of health disorders, and relationships with 305-day milk yield and conformation traits of registered Holstein cows. J. Dairy Sci. 81:2264-2270. https://doi .org/10.3168/JDS.S0022-0302(98)75806-0.

VanRaden, P. M. 1992. Accounting for inbreeding and crossbreeding in genetic evaluation of large populations. J. Dairy Sci. 75:3136-3144 https://doi.org/10.3168/JDS.S0022-0302(92)78077-1.

Waddington, D., S. J. Welham, A. R. Gilmour, and R. Thompson. 1994. Comparisons of some glmm estimators for a simple binomial model. Genstat Newsletter. 30:13-24. 